\title{
Estimation the Demand on Human Laborby Using Dual Approachin Iraqi Agricultural Sector
}

\author{
Eskander H. Ali \\ Eskanderhali81@gmail.com \\ LecturerEconomics Agricultural Dept. College of Agriculture Baghdad University
}

\begin{abstract}
There is no doubt thateconomic efficiency achieve when all the inputs factors use in an efficient way. The aim of this paper is determined the demand for Labor and the impact of the relationship between the Labor and Capital in the Iraqi agricultural sector during the period 1990-2014 rely on the dual approach by using the profit and cost models. To estimate the profit function it used the Cobb-Douglas model, and the results showed that the Labor demand elasticity for the worker's wage is -0.87 , and that means when the wages are rise about $10 \%$ the demand of Labor will reduce about 1.78\%. The cross-sectional elasticity between labor and capital is about 4.6, and that means for any increase in the capital such as 1\% led to increasing the labor by about $4.6 \%$. That confirms the hypothesis of this study where there is a substitutional relationship between the labor and capital for labor than capital, which means whenever to increase the capital or any technology improvement led to increasing the production and raises the investment. The labor demand function showed that the elasticity of the worker's wage for the value of the wages in the agricultural profit is about 0.462. That is mean when the employee's salary increase $1 \%$ the wages increase $0.462 \%$ from the profit, however; this rate is very low because of the agricultural sector depends on the family work regardless of the level of the wages. The cost function is determined too and used the Cobb-Doglegs model by using the Eviews.6 program. The results showed when the wages increase $1 \%$ the agricultural costs will increase too for about $16.2 \%$, and that is mean the Iraqi agricultural sector still have real problems of disguised unemployment. The study recommended to using the intensive technological ways to increase the worker productivity
\end{abstract}

Keywords: Cobb - Douglas Profit Function. Wages. Elasticity

\section{Introduction}

Human Resource Management is a key element in the majority of economic units that aims to appreciate the organizational capabilities of the individual, human resources can contribute to achieving the goals and profits of facilities and human resource management briefly means optimal use of the human element, how efficient and knowledge of this element andthe enthusiasm for work, in economic literature it is perceived as a basic productivity force to create new values represented in increasing investment opportunities, so it is an important productive resource, which its management is considered one of the most important dope of the administration jobs because of its focus on the human element, which is the most valuable and influential resource to the administration because it is one of the important and essential resources for the advancement of national product. If economic development was the nerve center of human development, thenthe human resources are the maker of economic development. Therefore, to achieve production efficiency it depends on the efficient use of production elements and the most important is labor item which has become holds a special place as an asset of the assets of the facility. The importance of the human element came from being the most important element of the production process, there must be good talent capable of distinct performance and giving, so we can say that the expansion of production is not only horizontal expansion but that the vertical expansion of production is complementary to the horizontal one, this is done by raising the level of productive efficiency by providing an educated human resources "because it is scientifically proven that worker productivity rises when increasing their educational level, the human element will be the most important factor while inventing new ideas and actual effects that lead to business growth and development, which is due to the individual economic growth and it is clear by increasing income.(Ali,2014).Working labor is consider one of the most important economic productivity resource for the advancement of agricultural production, so the economic efficiency depends on the efficient use of labor, which interacts with the rest of the production elements to determine the optimal combination of resources within the production process. Economic theory studied the labor by usingtheory of value considering that the basis of value due to the exerted workload in the production of goods, through studying the distribution of production elements theory onlabour, capital and determining their prices, and therefore know the extent of the contribution of these elements in the output and then estimate or derive the demand functions on the human element (Shehata and Mahmud ,2006). The demand for labor in economic theory is derived from demand on goods and services and not a final demand (Douglas et all,2008). Noting that the demand for labor depends on the prices of other production factors. Rising wages mechanization 
increases the demand for human labor and the technological change may lead to bring automation replaces human labor resulting in lower demand for labor (Connel and Stanley, 1995).

\section{Problem of the research:-}

In the agricultural sector, a large proportion of workers work, and it has the ability to absorb and operate a large proportion of the workforce, especially of non-working trainee or qualified technicians. But despite that, the proportion of the contribution of farm labour to the total labor is decreasing; this ratio was decreased from $47.1 \%$ in 1970 to $19.8 \%$ in 1991 and to $10.5 \%$ in 2009. In return, the technological changes did not occur to replace this drop. As a result of these forces remained non-contributing in the agricultural economic process, but it reflected the seriousness of unemployment in the countryside, and reflected in the decline in agricultural production, worker productivity, and the contribution of this sector to GDP, and in view of the prevailing economic relations between agricultural production factors, particularly between labor and capital, the research problem is represented in the nature of the demand for human labor.

\section{AIM OF THE RESEARCH:-}

The research aims to estimate the demand of human labor and the self, cross section and substitutionary elasticities of demand, to identify the nature of the relationship between the productionfactor.

\section{Research Hypothesis:-}

The research supposes the existence of excess in the use of labor resource with the substitution relationship between labor and capital at the expense of the capital resulting in an increased demand for labor but the response is less than the decline in demand at higher wages.

\section{Methods and Materials:-}

Dual Approach model has been applied in the search which depends on the profit and cost models to achieve the goals of the study, and several regression formulas are estimated to expand opportunities to choose results, then the best among them tested by economical, statistical andeconometric standards, the sources of data were obtained from official sources of the Ministry of Planning, the Central Bureau of StatisticsOrganization (CSO) as well as the Ministry of Agriculture - Planning Department.

\section{Results and Discussion:-}

The demand for human labor in the agricultural sector in Iraqwas estimated for the period from 1990 - 2014 in accordance with the dual approach using the profit and cost models through estimating Cobb-Douglas profitfunction model and cobb Douglas costs function, as follows:

Cobb-Douglas Profit Model:-

Cobb-Douglas profit functions and demand for resources take the following from (Chand and Kaul, 1986).

$$
\ln \pi=\alpha_{\mathrm{o}}+\sum_{\mathrm{i}=1}^{\mathrm{n}} \alpha_{\mathrm{i}} \ln \mathrm{P}_{\mathrm{i}}+\sum_{\mathrm{i}=1}^{\mathrm{m}} \beta_{\mathrm{i}} \ln \mathrm{Z}_{\mathrm{i}}
$$

The demand of the resource is derived from the demand of the produced commodity (Porto and Elia, 2015). And that the source request function get through solving the first derivative of the function of the profit equation No. 1 , which usually assume the case of the constant of returns to scale and thus put underrestrieetion the sum of elasticities is equal to the right one, so the profit function specification according to the following formula (Khan and Dennis, 1979), (Lovell, 1973):

$\ln л=\mathrm{a}+\mathrm{a}_{1} \ln \mathrm{WL}+\mathrm{B}_{1} \ln \mathrm{l} \ldots \ldots \ldots \ldots \ldots . . . \ldots$

Where л: representing the agricultural profit, which was obtained from raised workers' wages and production requirements which represented by variable capital from agricultural production value.

WL: represent workers' wages .k: representing the capital was obtained after estimating unit of capital and the division of production requirements on variable capital.

The model was estimated using ordinary least squares (OLS) and using the Statistical Eviewsprogram. The dual logarithmic formula was the best estimate of functions which pass statistical and econometrical tests and conform to the economic logic, Table 1 
Table 1 -Results Cobb - Douglas Profit function

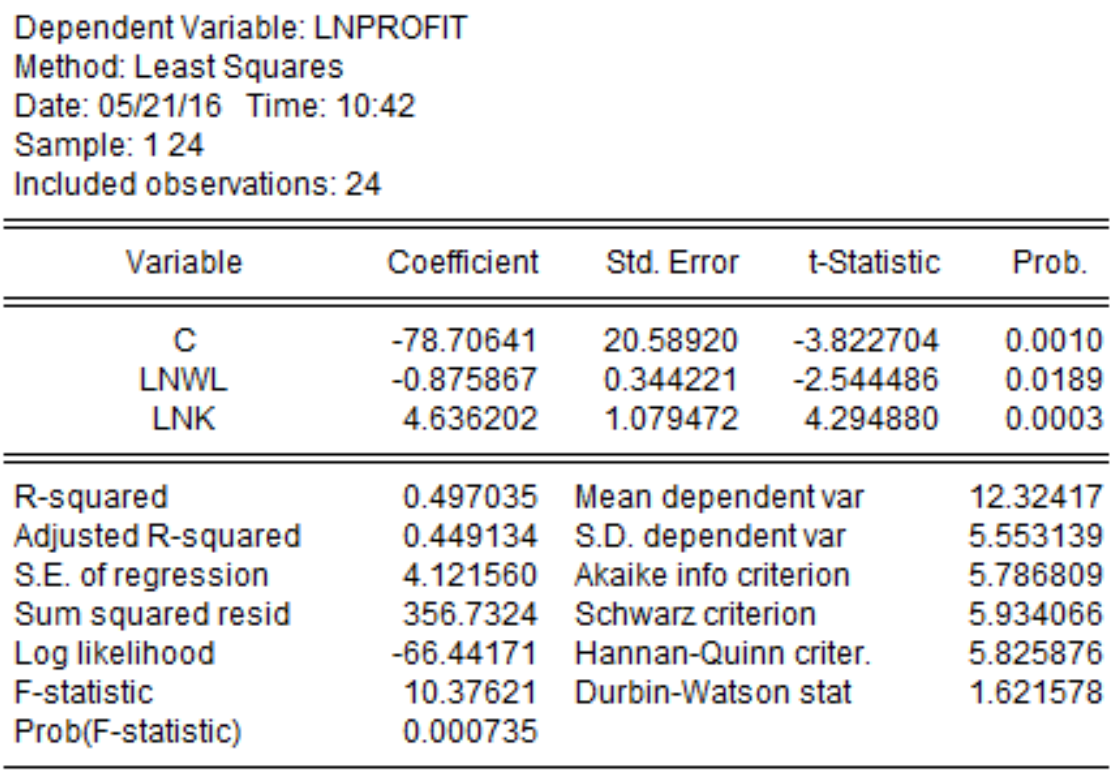

Source:prepared by of the researcher using the Eview.6.

Notes from Table 1 that the estimated function were identical with economic logic, and noting that the sign of worker's wage isnegative, and it was found that the elasticity of demand for human labor component for the worker's wage about"- -0.875 ". This means an increase in wages by $10 \%$ leads to lower demand of human labor by $8.75 \%$ with the constant of other factors in average, because economic theory suggests decreasing demand of source when increasing its price. And at higher wages costs increased which works on high output rate, and thus lower demand for them, this is what drives the producer to reduce production and thus reduce the demand of the labor (production effect). This is what supports the change in the purchase of the L unit with the change in its price(assuming other factors remain constant) always has a negative impact, and the crosssectional elasticity between labor and capital also amounted about 4.6, which explains that the capital increase by $1 \%$ leads to increased demand of labor by $4.6 \%$ this confirms the research hypothesis that the relationship between labor and capital is substitution in favor of working on the capital because it could be argued that the increase in capital or occurrence of technological change is working to increase production and thus creating investment opportunities resulting substantial effect as a decline in the costs of capital leads to lower production costs, and thus increase production and thus increase the demand of labor and, in general the increasing amounts of one factor leads to increased marginal product of the second supplier. This means that the increase in the price of one factor usually leads to reduced amounts used from the other factor. According to function of demand of labor the elasticity of the worker's wage for the wages valuable contribution in the agricultural profit $\left(\frac{a_{1-}}{D F}\right)$ about 0.462 , this means that the increase in worker's wage by $1 \%$ leads to increase the contribution of workers' wages in profit by 0.462 this percentage is low because of the reliance on family labor significantly in the agricultural sector regardless of the level of wages.AS elasticity's of production was calculated in Cobb Douglas profit model (Khan and Dennis,1979) where labor elasticity $\left.\frac{a_{1}}{1-a_{1}}\right)$ about $(-0.46)$ Which means that the increase in work item will reduce the value of agricultural production and from it we infer the existence of disguised unemployment in the agricultural sector as well as unskilled labor, To make sure that the inefficiency of this item achieves a sufficient condition of economic efficiency via equal to the marginal product value of work which about 8378.8 with the average real wage of the worker's which about 3605.2, showing that it can increase production quantities less than this factor. As for elasticity of capital $\left(\frac{B_{1}}{1-a_{1}}\right)(2.47)$ as it raised it by $1 \%$, the value of agricultural production will increase by $2.47 \%$ and this refers to the importance of capital to increase productivity the Positive sign of elasticity of the capital indicate that there is no waste of capital used and there is a possibility to increase it. Statistically proven the accepted function as a whole is at the level of $1 \%$, which demonstrates the real function through $\mathrm{F}$ test of 10.36 , while the explanatory variables were significant at the $1 \%$ level and those variables were able to explain $49 \%$ of the fluctuations in the value of agricultural production. The rest of the changes may be due to other factors not included in the model and they are many in the agricultural sector. The model to be accepted, a second-class tests are necessary to carry out for the detection of standard problems detecting autocorrelation problem was first done using test (LM) Breusch- Godfrey, which shows the acceptance of the null hypothesis, in other words any 
modelresiduallyhave a natural distribution thus the normal distribution requirement achieved thus the estimated model does not suffer fromthe problem of autocorrelation.

Although the data used are time series data that few of them are estimated to suffer from the problem of heteroscedasticity that these problems are linked with the Cross-sectional data often but it has been detected this problem by using ARCH test which explained the absence of a heteroscedasticity problem in the model. As shown by the Ramsey Reset test results there is no error identifying of the model, table 2 .

Table 2:Diagnostic tests ofthe second-class problems

Heteroskedasticity Test: ARCH

\begin{tabular}{llll}
\hline \hline F-statistic & 0.689411 & Prob. F(2,19) & 0.5140 \\
Obs*R-squared & 1.488509 & Prob. Chi-Square(2) & 0.4751 \\
\hline \hline
\end{tabular}

\begin{tabular}{llll}
\hline \hline Ramsey RESET Test: & & & \\
\hline \hline F-statistic & 11.86163 & Prob. F(1,20) & 0.0026 \\
Log likelihood ratio & 11.17609 & Prob. Chi-Square(1) & 0.0008 \\
\hline \hline
\end{tabular}

\section{Breusch-Godfrey Serial Correlation LM Test:}

\begin{tabular}{llll}
\hline \hline F-statistic & 2.794750 & Prob. F(2,19) & 0.0863 \\
Obs*R-squared & 5.455500 & Prob. Chi-Square(2) & 0.0654 \\
\hline \hline
\end{tabular}

Source: prepared of the researcher using the Eviews.6 program

As for Multiconllinearityuse the VIF test, which explained that the model does not suffer from the problem of multiple linear correlations with the value of 1.96 tests (Gujarti, 2004). Finally using the cumulative total test, showed that the variables structurally staticin the accepted level of5\% (Richard, 2015). Figure 1.

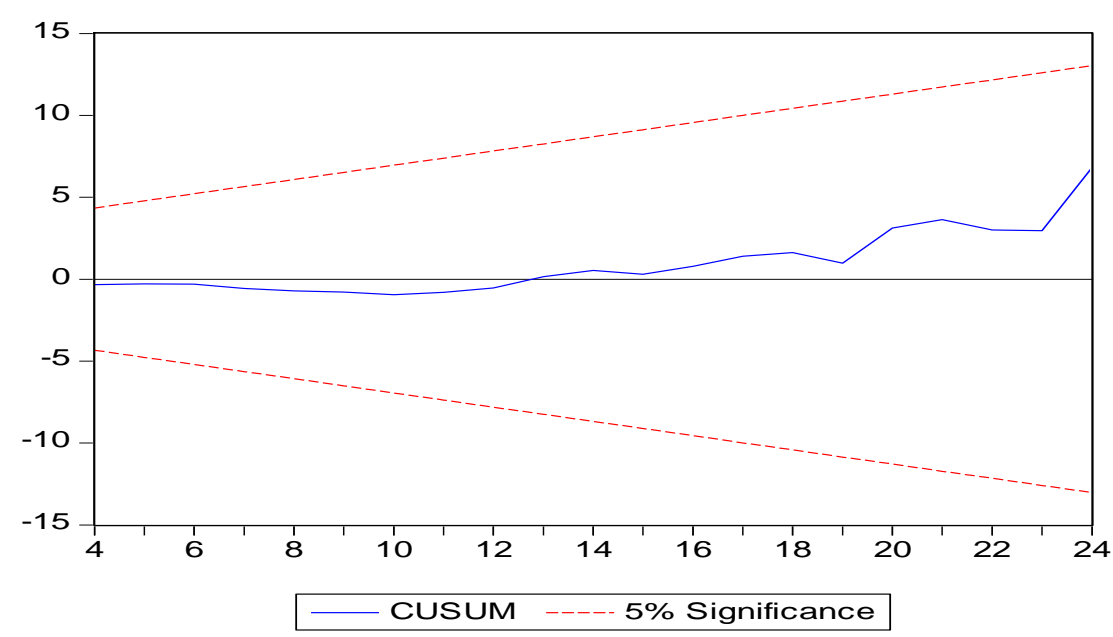

Figure 1: Cumulative total test

Source :Preparedby researcher work using Eviews.6

\section{2--Cobb - Douglas CostsModel:-}

The total cost function of any agricultural production project represents the relationship between the output of the project and the total costs; it consists of production factor prices and the value of output. Producer here seeks to minimize costs (Debertin, 2012)and the specimen takes the following formula (Greene,2007),(Berndt and Wood,1975).

$$
\ln \mathrm{C}=\alpha_{\mathrm{o}}+\sum_{\mathrm{i}=1}^{\mathrm{n}} \alpha_{\mathrm{i}} \ln \mathrm{P}_{\mathrm{i}}+\beta \ln \mathrm{Y}
$$

As the 
C: Agricultural production costs. P: Unit price of agricultural output. Y: Agricultural output value. That functionsof demand for labor and capital will estimate by derivation of Cobb-Douglas costs function for worker's wage $\mathrm{W}$ and the unit price of capital $\mathrm{R}$ as follows.

Lnc $=b_{0}+b_{1} \ln w+b_{2} \ln r+b_{3} \ln y$ . .4

The model was estimated using Eviews6.and depending on the method of OLS. Table 3 shows the results of the estimated model.

Table3-Results Cobb-Douglas cost function results

\begin{tabular}{|c|c|c|c|c|}
\hline Variable & Coefficient & Std. Error & t-Statistic & Prob. \\
\hline $\mathrm{C}$ & -1.863072 & 4.848565 & -0.384252 & 0.7048 \\
\hline LNW & 1.621029 & 0.261804 & 6.191758 & 0.0000 \\
\hline LNR & -0.111169 & 0.055731 & -1.994743 & 0.0599 \\
\hline LNY & 0.020910 & 0.329722 & 0.063417 & 0.9501 \\
\hline R-squared & 0.818475 & \multicolumn{2}{|c|}{ Mean dependent var } & 10.52667 \\
\hline Adjusted R-squared & 0.791246 & \multicolumn{2}{|c|}{ S.D. dependent var } & 2.455260 \\
\hline S.E. of regression & 1.121799 & \multicolumn{2}{|c|}{ Akaike info criterion } & 3.218756 \\
\hline Sum squared resid & 25.16865 & \multicolumn{2}{|c|}{ Schwarz criterion } & 3.415098 \\
\hline Log likelihood & -34.62507 & \multicolumn{2}{|c|}{ Hannan-Quinn criter. } & 3.270846 \\
\hline F-statistic & 30.05916 & \multirow{2}{*}{\multicolumn{2}{|c|}{ Durbin-Watson stat }} & 2.440378 \\
\hline Prob(F-statistic) & 0.000000 & & & \\
\hline
\end{tabular}

Source: prepeardResearcher work using Eviews.6 program

From Table 3 can be seen economic variables studied which economic logic in terms of its signal as the worker's wage increase by $10 \%$, the agricultural production costs will increase by $16.2 \%$, while increasing the price of capital by $10 \%$ lead to lower costs by $1.1 \%$, this may be irrational, but can be justified by the possible need of the agricultural sector for more varieties of new technology, machinery, equipment and mechanization, which is lacking in the sector. So this increase is absorbed by the sector and it is clear that labour wages is one of the most influential factor in the increased costs to the presence of an increase in manpower, resulting in disguised unemployment, statistically the value of t. showsignificant of elements worker's wage and price of capital at the level of 1 and 5\% respectively, and the estimated modelaccepted as a whole at the level of $1 \%$ according to $F$ test which its value amounting 30.05, which reflects realistic of the specimen and the importance of variables, as the determination coefficient showed that the explanatory variables explained $81 \%$ of the fluctuations in agricultural production costs, and $19 \%$ of the changes belong to other factors not measured in the model. The elasticity of demand of labor and capital reached -88 and- 5.5, this means that the increase in the price of each of them reduces the demand of them by 88 and $5.5 \%$, this percentage is high for the labour, but may be due to the weakness of production and the deterioration of the reality of the agricultural sector, which has been reflected in the weakness of productivity as low elasticity appeared led to the large size of labor and capital elasticities.

The estimated model to be acceptable and can be relied upon autocorrelation problem was detected and it is found that the model residuals have a normal distribution according to the Jarque-Bera test as its value amounted 1.263 which is greater than 5\% and which accept the null hypothesis. The problem of Multicollinearity was detected by using inflation coefficient of variation Inflation test which explained the absence of this problem and it was worth 5.26, also the model free of heteroscedasticity problem as shown by Whit test whichit's value is 6.393 it is less than its counterpart in tabular Chi-square, and therefore accepted the null hypothesis. Figure 2. 
Figure 3: diagnostic tests of the model

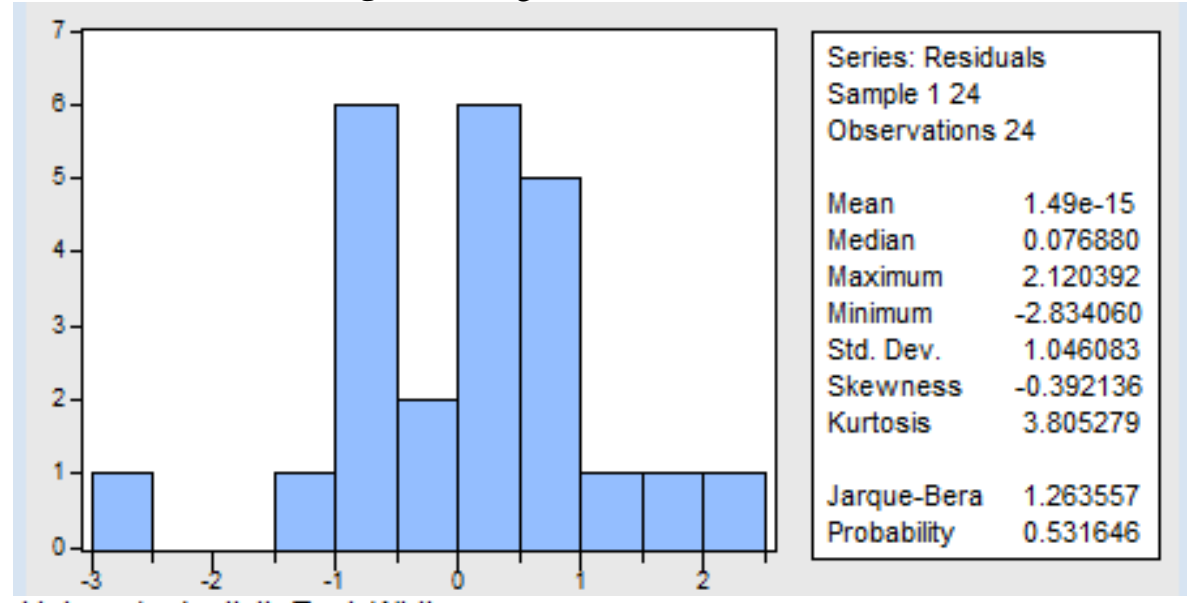

Heteroskedasticity Test: White

\begin{tabular}{llll}
\hline \hline F-statistic & 0.564853 & Prob. F(9,14) & 0.8041 \\
Obs*R-squared & 6.393330 & Prob. Chi-Square(9) & 0.7000 \\
Scaled explained SS & 6.227457 & Prob. Chi-Square(9) & 0.7170 \\
\hline \hline
\end{tabular}

Source: PrpearedResearcher work using Eviews.6

We conclude from the research the importance of the capital, and it has the huge impact in the profit function and it can increase production quantities less from the labor resource, and the increase in worker's wage does not affect much in the contribution of the worker's wage in profit, and the response to the decreasing demand is less at higher wages, the research indicated a substitution relationship between the labor and capitalresulted in a productive effect and substitution effect. Accordingly research recommends of application of intensive technology methods in the capital and the expansion of projects, and the establishment of new projects to create and absorb surplus labor with attention to the labour factor and focus on its role in agricultural development and development and training of it and working to increase its productivity.

\section{References}

[1]. Ali, E. H. 2014. Measuring of Economic efficiency and determining the economic size of farms in diyala province. ph. D. Dissertati-on. Dept of Agr. Eco.Coll. of Agr. Baghdad University.in Arabic pp. 220

[2]. Berndt, E. and D. Wood .1975.Technology Price and the derived demand for energy . Rev.Eco.and.Stat.V.57,N.3 P:2259-2268.

[3]. Brownson, A., P. Lnimfon and U. Samuel. 2012. Stochastic profit efficiency of Homestead based cassava farmers southern Nigeria. Jo. ofAgr. And Rural Development .2(3).pp:498-505

[4]. Chand, R. and J. Kaul. 1986. A Note on the use Cobb - Douglas profit function . Am. J. Agr.Econ.V.68 ,N.1,P:162-164

[5]. Connel, C. and L. Stanley. 1995.Contemporary Labor Economics .4 ${ }^{\text {th }}$ edMcGraw- Hill Book Company Inc .USA.pp:330.

[6]. Debertin , David. L. 2012. Agricultural production Economic .Second Edition Macmillan Publishing Company, USA. PP. 366.

[7]. Douglas, B. ,Bernheln and Michael. D. Whiwston .2008. Microeconomic. Mc- Graw.Hill.

[8]. Greene, W. 2007.Econometric Analysis . $6^{\text {th }}$ ed. New Jersey. Pearson prentice Hall.

[9]. Gujrati, N.D. 2004 .Basic Econometrics - Mc- Graw Hill Co. Press . LTD. pp: 1024.

[10]. Khan, M. and R. Dennis .1979. Effects of farm size on economic efficiency : the case of Pakistan. Am. J. Ag. Econ. V.61,N.1.P:6469.

[11]. Lovell, C. 1973.CES and VES production function in a cross-section context .Jo. Polit. Econ. V.81,P:705-720.

[12]. Porto. E. and L. Elia. 2015. Estimating labor demand function in the presence undeclared labor. Working paper .N.389.CSEF .Italy,pp:1-37.

[13]. Richard, S. 2015.Eviews lustrated for version 9.IHS Global Inc. pp:441.

[14]. Shehata, E. and S. Mahmud. 2006. Performance efficiency of the Human Labor Input in the Animal Production Sector (A case study) . Journal of Contemporary Egypt ,N.482,p: 525 - 552. 